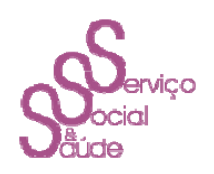

\title{
DERECHOS HUMANOS, SALUD Y TRABAJO SOCIAL: MUJERES MIGRANTES PRÓXIMAS A REDES DE TRATA EN ESPAÑA
}

\author{
HUMAN RIGHTS, HEALTH AND SOCIAL WORK: INMIGRANTS WOMEN POTENTIAL \\ VICTIMS OF TRAFFICKING IN SPAIN
}

DIREITOS HUMANOS, SAÚDE E TRABALHO SOCIAL: MULHERES MIGRANTES

PRÓXIMAS ÀS REDES DE TRÁFICO NA ESPANHA

\author{
Nuria Cordero Ramos ${ }^{1}$ \\ Carmen Fernández Esquivel ${ }^{2}$
}

\begin{abstract}
RESUMEN
El objetivo principal es visibilizar las dificultades que tienen las mujeres migrantes posibles víctimas de trata para ejercer su derecho a la salud en España, además de reflexionar como el Trabajo Social puede contribuir para superarlo. Partiremos del concepto de trata de personas y la vulneración que esta supone de los Derechos Humanos, analizando la normativa Internacional, Nacional y Autonómica en materia de salud y trata, observando cómo el derecho a la salud no está siendo considerado como un derecho universal en España, afectando a las mujeres posibles víctimas de trata, entre otros. Y por último, mencionaremos el papel general de los trabajadores sociales frente a este fenómeno.
\end{abstract}

PALABRAS CLAVE: Trata de mujeres. Inmigrantes. Derechos Humanos. Salud. Trabajo Social.

\section{RESUMO}

O objetivo principal é dar visibilidade às dificuldades enfrentadas pelas mulheres migrantes possíveis vítimas de tráfico para exercer seu direito à saúde na Espanha, além de refletir como o Trabalho Social pode contribuir para superá-lo. Partiremos do conceito de tráfico de pessoas e a vulnerabilização que esta supõe aos Direitos Humanos, analisando a legislação internacional, nacional e autonômica em matéria de saúde e de tráfico, observando como o direito à saúde não está sendo considerado como um direito universal na Espanha, afetando as mulheres potenciais

\footnotetext{
${ }^{1}$ Profesora Titular del Departamento de Trabajo Social y Servicios Sociales, Universidad Pablo de Olavide, Sevilla, España. E-mail: ncorram@upo.es

${ }^{2}$ Graduada en Trabajo Social, Universidad Pablo de Olavide, Sevilla, España. E-mail: carmen_cfe@hotmail.com.
}

Serv. Soc. \& Saúde, Campinas, SP v.15, n. 2 (22), p. 179-200, jul./dez. 2016 ISSN 1676-6806 
vítimas de tráfico, entre outros. E, finalmente, mencionaremos o papel geral dos trabalhadores sociais frente a este fenômeno.

PALAVRAS-CHAVE: Tráfico de Mulheres. Imigrantes. Direitos Humanos. Saúde. Trabalho Social.

\begin{abstract}
The purpose of this work is to expose the difficulties that sub-saharan women potential victims of trafficking have to face when trying to exercise effectively their health rights in Spain, in addition to reflect on the contributions that the social work can be done to overcome it. We should start from the concept of human trafficking and the violation of human rights that this represents. An analysis of the evolution of the International, National and Regional legislation on health and trafficking will be made, observing how the right to health is not being considered as a universal right in many of the regions of Spain, affecting potential female victims of trafficking, among others. Finally, we will mention the general role of social workers in this phenomenon.
\end{abstract}

KEYWORDS: Trafficking of Women. Immigrants. Human Rights. Health. Social Work.

\title{
INTRODUCCIÓN: LA TRATA CON FINES DE EXPLACION SEXUAL EN ESPAÑA
}

Aunque el fenómeno de la trata de personas no se consideró como problema social y público a partir del siglo XX, estamos ante una cuestión social tan antigua como la propia esclavitud, donde se priva a las personas de tener una vida digna (CORDERO, 2014; CASTRO, 2012).

La definición de Trata aparece recogida en diversos instrumentos internacionales como en el Protocolo de Palermo (2000) y en el Convenio Europeo contra la Trata de Seres Humanos (2005). En el Protocolo de Palermo (2000, p. 5) se define la trata de personas como:

[...] la contratación, la captación, el transporte, el traslado, la acogida o recepción de personas, utilizando la violencia, amenazas, engaño, rapto, el abuso de poder o abuso de la situación de vulnerabilidad u otros elementos de coacción con el fin de someterla a explotación y lucrarse con su actividad.

En referencia a la definición anterior podemos decir que el objetivo principal de este fenómeno es la explotación del ser humano con vistas a ganar dinero o favores a costa de las víctimas. 
Pero ¿a qué tipos de explotación nos referimos? Abdulraheem y Oladipo (2010) lo comentan: "Exploitation shall include, at a minimum, the exploitation of the prostitution of others or other forms of sexual exploitation, forced labor or services, slavery or practices similar to slavery, servitude or the removal of organs" (ibid., p. 35). Siguiendo las aportaciones de estos autores, podemos decir que la explotación de la víctima puede revestir diversas formas: explotación sexual, laboral, tráfico de órganos, mendicidad y otras prácticas semejantes. Dentro de los ámbitos de la explotación referidos a la trata, se puede decir que la más notable es la trata de personas con fines de explotación sexual (trabajar en prostíbulos, salones de masajes, circuitos de prostitución, entre otros). Asimismo, las principales víctimas de esta tipología de trata en España son mujeres extranjeras, siendo especialmente vulnerables las que se hallan en situación irregular (CORDERO, 2014; ACUÑA y otros, 2012; ACCEM, 2011).

Factores estructurales como son la feminización de la pobreza y de las migraciones, el mercantilismo y la dominación patriarcal, dan las claves para comprender el significativo aumento del número de mujeres inmigrantes del África Subsahariana que en los últimos años están llegando al territorio español (MALENO, 2010). Las aportaciones de Acién y Checa (2011) ponen también el acento en el anhelo de las personas procedentes de países empobrecidos por inmigrar a otros lugares con unas mejores condiciones económicas con el fin de construir un futuro mejor y, así, poder enviarle dinero a su familia de origen. Durante el proceso migratorio algunas mujeres son reclutadas por las redes mediante estrategias como falsas ofertas de trabajo u ofertas engañosas que no aclaran las condiciones en las que se va a realizar el trabajo ofrecido. No obstante, una vez que llegan a los lugares de destino son explotadas ejerciendo el trabajo sexual en condiciones de explotación. Con esta afirmación no queremos decir que todas las mujeres migrantes acaben formando parte de una red de explotación sino que queremos señalar que las políticas migratorias favorables al cierre de fronteras en Europa, aumenta la vulnerabilidad de las mujeres migrantes para convertirse en foco de interés para las redes de trata de personas.

Según el Informe del Ministerio de Sanidad, Servicios Sociales e Igualdad (2015-2018), la mayoría de las víctimas de trata de personas proceden de la UE (65\%), principalmente de Bulgaria, Rumanía, Holanda, Polonia y Hungría. Gran parte de las víctimas de países no pertenecientes a la UE proceden de Nigeria, Brasil, China, 
Vietnam y Rusia. En cuanto a la nacionalidad, Rumania es, al igual que en 2013, el país con mayor número de posibles víctimas (el 32\%), seguida de Nigeria, país de origen del 27\% de las mujeres que presentan indicios de trata con fines de explotación sexual y, en menor medida República Dominicana (5\%), Brasil (5\%), Bulgaria (4\%) y Paraguay (4\%). Como se refleja en la ilustración siguiente, llegan mujeres a España procedentes América del Sur, África Subsahariana y Asia oriental:

Ilustración 1. Principales zonas de destino de las corrientes de trata transregionales (en azul) y principales orígenes

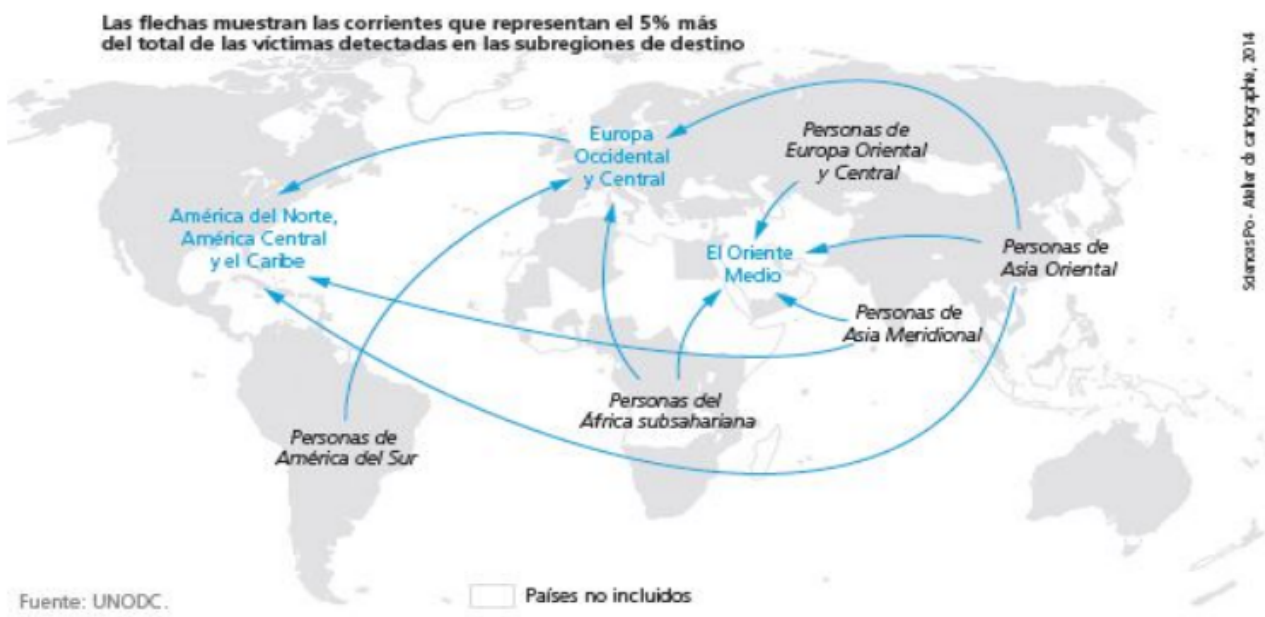

Fuente: UNODC, 2014, p. 7.

Vemos como existe una correlación entre la riqueza (PIB) del país de destino y la proporción de las víctimas de la trata trasladadas allí desde otras regiones. Los países más ricos atraen a víctimas de diferentes orígenes, incluso de otros continentes, mientras que en países menos prósperos se observan principalmente corrientes de trata nacionales o subregionales.

En el caso concreto de España y siguiendo las aportaciones realizadas por el Informe del Defensor del Pueblo (2012), aunque las rutas son cambiantes, una de las rutas que predomina hasta el momento en nuestro país es la ruta subsahariana, siendo los países destino Italia, Países Bajos, Bélgica y España. Otro trayecto que destaca es el que une Rumanía con Europa Occidental, representando el perfil más común a una mujer de nacionalidad rumana entre los 18 y 32 años de edad. Por último destacar que Serv. Soc. \& Saúde, Campinas, SP v. 14, n. 2 (20), p. 179-200, jul./dez. 2015 ISSN 1676-6806 
se ha venido descubriendo un perfil de mujeres de nacionalidad brasileña entre los $33 \mathrm{y}$ 42 años de edad. Importante destacar que Brasil se considera como un país origen de trata para hombres, mujeres y niños víctimas de trata con fines de explotación sexual.

En cuanto a nuestra Comunidad Autónoma de Andalucía, la mayor parte de las personas que llegan a nuestra tierra provienen de zonas y países donde se da con continuidad los conflictos bélicos, suelen ser países como Nigeria, Sierra Leona y Ghana (DEFENSOR DEL MENOR, 2013).

Estas redes transnacionales operan a través de intermediarios que logran mantener el control de las mujeres utilizando la violencia física, amenazas a los familiares que se quedaron en sus lugares de origen, además de otros medios, como la retirada del pasaporte, del dinero así como el desconocimiento de la lengua y de los recursos que existen en España para apoyarlas. Todo esto hace que su única alternativa que encuentran sea la de someterse a la explotación para saldar la deuda contraída soliendo rondar los 45.000 euros (CASTELLANOS y RANEA, 2014; ANGUITA, 2007).

Las mujeres migrantes víctimas de trata se encuentran en una línea que recorre las zonas de vulnerabilidad y exclusión (CASTEL, 2010) y que viene definida por las condiciones de desigualdad que soportan en los lugares de origen y anhelo por llegar a un lugar donde les permita vivir en mejores condiciones.

\section{LA TRATA DE PERSONAS COMO UNA VIOLACIÓN DE DERECHOS HUMANOS}

La inquietud internacional por la cuestión de la trata tiene sus antecedentes más inmediatos, en la primera Convención moderna sobre la Esclavitud, elaborada por la Sociedad de Naciones en 1929. Más tarde, será la Declaración Universal de los Derechos Humanos en 1948 la que ponga el acento en la libertad, igualdad y dignidad de todos los seres humanos rechazando así, cualquier forma de esclavitud. En 1949, la Asamblea General de las Naciones Unidas proclama el Convenio para la represión de la trata de personas y la explotación de la prostitución ajena. La importancia de este documento es que amplía a todas las personas, y no sólo a las mujeres y niños, la posibilidad de padecer situaciones de trata. Dicho Convenio condena la prostitución o 
su incitación, aunque hubiera consentimiento (JULIANO, p. 2005). Desde entonces, y hasta la actualidad la confusión entre trata con fines de explotación sexual y prostitución sigue presente tanto en discursos institucionales como en las propuestas políticas de lucha contra la trata.

A partir del año 2000 se retoman los esfuerzos - encabezados por las Naciones Unidas (ONU) - para enfrentar los diferentes tipos de esta forma de explotación humana $^{34}$. Entre los objetivos estaba el establecer una coordinación efectiva entre países con el propósito de obtener datos veraces y desarrollar y aplicar medidas legales para combatirla. En concreto, se crea el ya mencionado Protocolo para prevenir, reprimir y sancionar la trata de personas, más conocido como Protocolo de Palermo.

En el ámbito europeo, es el Convenio del Consejo de Europa sobre la Lucha contra la Trata de Seres Humanos de 2005, el que asume las directrices marcadas por el Protocolo de Palermo. Este Convenio junto a la Directiva de la Unión Europa de 2011 constituyen el marco en el que España fundamenta su respuesta al fenómeno de la trata de seres humanos con fines de explotación. Dicho Convenio hace alusiones claras a la vulneración de derechos que supone la trata de personas:

En efecto, la trata de seres humanos constituye uno de los atentados más intolerables contra los derechos humanos, significadamente en cuanto lesiona gravemente la dignidad de la persona (CONSEJO DE EUROPA, 2005, p. 2).

La incidencia directa del Consejo de Europa (2005) en la legislación española se aprecia en la modificación en el Código Penal en 2010 que tipifica la trata como delito y en una modificación en la Ley de extranjería LOEX (2011) que reconoce la necesidad de protección a las víctimas de trata.

En el caso concreto de España no existe una ley nacional contra la trata, sin embargo el Ministerio del Interior lanzó, en 2008, el I Plan Integral de Acción contra la trata de seres humanos con fines de explotación sexual. Análisis de situación y Plan de Acción. La validez de este Plan es la de ser el primer documento normativo a nivel

\footnotetext{
${ }^{3}$ Ese año se celebró la Convención contra la Delincuencia Organizada Transnacional y se elaboraron tres protocolos, precisamente uno de ellos, el conocido como el Protocolo de Palermo, está destinado a prevenir, reprimir y sancionar la trata de personas, especialmente mujeres y niños (ONU, 2000, p. 2).
} 
nacional que trata de desarrollar las recomendaciones del Consejo de Europa aunque el desarrollo de medidas integrales para la atención de las víctimas se menciona en el capítulo segundo, en la práctica se queda más bien en una declaración de intenciones (CORDERO, 2014, p. 7).

El II Plan Integral de lucha contra la trata de mujeres y niñas con fines de explotación sexual (2015-2018) lo promueve el Ministerio de Sanidad, Servicios Sociales e Igualdad. Este documento recoge las recomendaciones y aportaciones a partir de informes de organismos internacionales y en los diferentes foros de consulta también a las asociaciones y ONGs. El Segundo Plan plantea como objetivo la promoción de los derechos humanos y protección de las víctimas. Reconoce como pilares de su Plan de Acción un enfoque de derechos humanos, enfoque de género, primacía del interés superior del menor, la mejora del conocimiento de las situaciones de trata con fines de explotación sexual, el protagonismo de las víctimas, la persecución del delito y un enfoque integral de cooperación y participación (CORDERO, ANTOLÍNEZ y JORGE, 2015, p. 13).

Aunque las mencionadas acciones políticas suponen un avance en el reconocimiento del problema, no han generado la implementación de políticas públicas preventivas o que garanticen una atención integral a las personas que padecen situaciones de trata. Prevaleciendo el interés por la persecución del delito antes que el restablecimiento de los derechos de las personas. Todo ello provoca que exista un bajo porcentaje de mujeres que se acojan a los programas de intervención y a los instrumentos jurídicos existentes en la legislación española para su protección (DEFENSOR DEL PUEBLO, 2012).

Además, en el caso de la Frontera Sur (con África) el gobierno español se limita a la intercepción de documentación ilegal y persecución de la prostitución en lugares públicos. Estas medidas de control agudizan las graves vulneraciones de derechos humanos que padecen las mujeres migrantes que llegan a territorio español, incluyendo las acciones violentas de los cuerpos y fuerzas de seguridad del estado español y marroquí.

Apelar a la defensa de los Derechos Humanos de las mujeres migrantes próximas a redes de trata requiere partir de una noción crítica y actualizada de los mismos, superadora del enfoque punitivo y post violatorio. Tomamos como referente la Serv. Soc. \& Saúde, Campinas, SP v.15, n. 2 (22), p. 179-200, jul./dez. 2016 ISSN 1676-6806 
propuesta del profesor Joaquín Herrera para explicar que son los derechos humanos para la teoría crítica:

[...] serían los resultados siempre provisionales de las luchas sociales por la dignidad. Entendiendo por dignidad, no el simple acceso a los bienes, sino que dicho acceso sea igualitario y no esté jerarquizado a priori por procesos de división del hacer que colocan a unos en ámbitos privilegiados a la hora de acceder a los bienes y a otros en situaciones de opresión y subordinación (HERRERA, 2005, p. 26).

Esta posición plantea una nueva mirada que rompe con las teorías tradicionales de derechos humanos, donde los valores de la igualdad, la libertad y la ciudadanía recaen sobre un sujeto abstracto de derecho, que es varón, blanco, burgués, heterosexual, recogida por autores como Herrera (2005), Sánchez y Senent (2013) y que fondea en el imaginario de las Convenciones Internacionales aprobadas y ratificadas por los países europeos. Desde la teoría crítica se ponen en valor la diversidad de las realidades sociales y culturales de las comunidades que pueblan el plantea cuya pretensión es la de rescatar los procesos de lucha de quienes no tienen acceso a los recursos materiales e inmateriales para una lograr existencia digna y acciones transformadoras.

Las aportaciones de la teoría crítica de los derechos humanos, para el tema que nos ocupa, han de ser complementadas con las aportaciones del pensamiento decolonial de Grosfoguel (2014), Quijano (2014), Sousa y Meneses (2014), con el fin de cuestionar las lógicas coloniales de dominación y de explotación que siguen operando de forma hegemónica en las relaciones Norte-Sur. Las variables de etnia, clase social y género se cruzan y operan como categorías de dominación entre países del Norte y del Sur. Estas relaciones están impregnadas por miradas eurocéntricas y androcéntricas convirtiendo, de forma naturalizada, a los países del Norte, en dominadores y explotadores y a los países del Sur en dominados y explotados.

Estas dinámicas geopolíticas de poder y dominación se despliegan en todas los ámbitos de las relaciones humanas: sexual, social, político. Como plantea Lugones (2013) además de la necesidad de hacer un vuelco decolonial de la geopolítica también es necesario hacer el vuelco en la corporalidad política, entendiendo que el género y la sexualidad operan a su vez dentro de la matriz colonial que llega desde los llamados feminismos subalternos representados por Lugones (2008) y Sousa y Meneses (2014), Serv. Soc. \& Saúde, Campinas, SP v. 14, n. 2 (20), p. 179-200, jul./dez. 2015 ISSN 1676-6806 
entre otras. A partir de estos planteamientos llama la atención como los cuerpos de las mujeres del Sur son explotados como mercancía para cubrir demandas y necesidades procedentes de los países del Norte.

Nuestra posición, desde la teoría crítica de los derechos humanos señalamos que las condiciones de desigualdad de contexto generadas por el propio sistema capitalista y patriarcal son un factor fundamental a la hora de entender este fenómeno.

Las principales vulneraciones de derecho a las que se enfrentan las mujeres migrantes próximas a las redes de trata se pueden sintetizar brevemente de la siguiente manera:

- Vulneraciones de derechos propias de los lugares de origen: situaciones como pobreza, desempleo, matrimonios forzosos, guerras, conflictos armados y catástrofes naturales que se dan en sus países de origen.

- Vulneraciones de derecho producidas en el tránsito migratorio : caracterizado por arduos trayectos a pie o en precarios medios de transporte; falta de agua, comida y servicios básicos; duras condiciones climatológicas; duras condiciones sanitarias dependiendo de si permanecen en las ciudades o en los bosques; agresiones físicas y/o sexuales; retención o carencia de documentación acreditativa que las coloca en posición de vulnerabilidad en las fronteras; tratamiento arbitrario y/o vejatorio por parte de las Fuerzas y Cuerpos de Seguridad de los diferentes países etc.

- Vulneraciones de derechos producidas en los países de destino: situaciones de irregularidad, coacción y perpetuación de la deuda por parte de los y las tratantes o intermediarios, desconocimiento del idioma y de las claves culturales del país al que llegan, xenofobia por parte de la población receptora, falta de redes de apoyo, etc.

De todas estas vulneraciones de derechos elegimos centrar nuestra atención en el derecho a la salud y las dificultades para disfrutarlo, por parte de estas mujeres, en España. 


\section{DERECHO A LA SALUD PARA LAS MUJERES MIGRANTES: NORMATIVA INTERNACIONAL, NACIONAL Y AUTONÓMICA}

Antes de abordar la normativa existe, nos parece necesario hacer explícito que entendemos por salud. Según la definición de la Organización Mundial de la Salud (OMS, 1948) "la salud es un estado de completo bienestar físico, mental y social, y no solamente la ausencia de afecciones o enfermedades” (p. 1). Ahora bien, ¿Cómo se puede llegar a disfrutar del este derecho?

Existe una serie de normativas internacionales, nacionales y autonómica andaluza sobre la regulación del derecho a la salud, la asistencia socio-sanitaria y la atención a las mujeres víctimas de trata desde hace unos años hasta el día de hoy, dónde apreciamos la evolución y los cambios que se han producido en materia de salud y trata. Podemos decir que el marco regulador del derecho a la salud en España no se agota con la Constitución y con la normativa jurídica interna sobre el tema, como veremos a continuación. Existen normas de Derecho Internacional de los Derechos Humanos de las que España es parte y que contemplan el reconocimiento del derecho de prestación sanitaria.

Sin embargo, podemos decir que la actual reforma sanitaria (Real Decreto-ley 16/2012) supone una vulneración de muchas de ellas, entre otras, del "Pacto Internacional de Derechos Económicos, Sociales y Culturales" suscrito por España, en la cual vulnera la asistencia universal a la seguridad social y a la salud (LEMA, 2014).

Este mismo autor nos señala que:

[...] se ignoran las obligaciones internacionales derivadas de los Tratados Internacionales ratificados por España, que exigen e interpretan la configuración del derecho a la salud como un derecho fundamental de todas las personas, con independencia de su situación administrativa" (LEMA, 2014, p. 99).

Ante este panorama podemos decir que distintas organizaciones, como Amnistía Internacional o Médicos del Mundo, han denunciado la actual reforma sanitaria por suponer una violación de los derechos humanos, limitando el derecho a la salud de algunos colectivos como son las mujeres inmigrantes sin papeles.

Respecto al ámbito nacional, la aprobación por parte del Gobierno Español del "Real Decreto-ley 16/2012, de 20 de abril, de medidas urgentes para garantizar la Serv. Soc. \& Saúde, Campinas, SP v. 14, n. 2 (20), p. 179-200, jul./dez. 2015 ISSN 1676-6806 
sostenibilidad del Sistema Nacional de Salud y mejorar la calidad y seguridad de sus prestaciones", supuso un gran cambio del derecho a la salud en España, al limitar la titularidad de éste a una condición administrativa y dejar sin cobertura sanitaria gratuita a los inmigrantes en situación administrativa irregular, afectando sobre todo a las mujeres por su situación de vulnerabilidad, y, negando la universalidad sanitaria que planteaban ya entonces las leyes y normas precedentes a la misma.

Hasta la imposición de este Real Decreto-Ley 2012, han existido una serie de leyes y normas que regulaban el derecho a una asistencia sanitaria gratuita para todo el mundo, de las cuales podemos mencionar algunas de ellas:

- El punto de inflexión se produce en 1986, con la aprobación de la Ley 14/1986, de 25 de abril, General de Sanidad, en la cual tienen derecho a la protección de la salud y a la atención socio-sanitaria todos los españoles y extranjeros que tengan establecida su residencia en el territorio nacional.

- Además, vemos como después la Ley Orgánica 4/2000, de 11 de enero, sobre derechos y libertades de los extranjeros en España y su integración social garantiza a los extranjeros sin permiso de residencia y/o trabajo el derecho a la asistencia sanitaria.

- Después, observamos la aprobación de la Ley 16/2003, de 28 de mayo, de cohesión y calidad del Sistema Nacional de Salud (que ha sido modificada por el Real Decreto-ley 16/2012 tal y como veremos a continuación).

- Y la Ley 33/2011, de 4 de octubre, General de Salud Pública, confirma la senda de sus predecesoras, garantizando este derecho a todo el mundo.

Todas estas leyes mencionadas suponen la confirmación hacia la universalidad del derecho a la salud, vinculando el derecho a la salud y a la atención socio-sanitaria a la persona, al ciudadano y no a la condición de asegurado como veremos a continuación. Sin embargo, es necesario señalar que a pesar de esta evolución normativa conducente a la universalización del derecho a la salud, la realidad social ofrecía un panorama sumamente distinto, por ejemplo, promoviendo el endurecimiento de los requisitos para la obtención de la tarjeta sanitaria (LEMA, 2014; MÉDICOS DEL MUNDO, 2014; AMNISTÍA INTERNACIONAL, 2012). Ahora bien, ¿Qué cambios se han producido tras la implantación del Real Decreto-ley 16/2012? Según Lema (2014) 
esta norma supone una modificación radical de la "Ley 16/2003, de 28 de mayo, de cohesión y calidad del Sistema Nacional de Salud", en concreto de su artículo 3, en el que pasamos de tener asistencia socio-sanitaria gratuita universal a garantizarse exclusivamente a aquellas que ostenten la condición de asegurado.

Por lo que antes de la entrada en vigor del Real Decreto-ley 16/2012 bastaba con que los ciudadanos extranjeros estuvieran empadronados en cualquiera de los municipios de España. Ahora, con la entrada en vigor de esta norma, para seguir manteniendo la tarjeta sanitaria tienen que cumplir la condición de asegurado (LEMA, 2014; MÉDICOS DEL MUNDO, 2014).

Al mismo tiempo, es necesario preguntarse ¿cuáles son los requisitos para tener la condición de asegurado? El Real Decreto-ley 16/2012 considera que tienen la condición de asegurados:

[...] trabajadores por cuenta propia o ajena, pensionistas, perceptores de una prestación periódica de la seguridad social, personas que han agotado la prestación o el subsidio de desempleo u otra prestación de naturaleza similar siempre que se encuentren en el paro.

En resumidas cuentas podemos afirmar que el derecho a la salud deja de ser universal para estar supeditada a la condición de asegurado y las personas inmigrantes en situación administrativa irregular pasan a estar excluidas del Sistema Nacional de Salud.

Según este Decreto las personas sin tarjeta sanitaria sólo serán atendidas en los siguientes casos:

a) "Urgencias por enfermedad grave o accidente, hasta que se produzca el alta médica".

b) "Asistencia socio-sanitaria durante el embarazo, parto y postparto".

Sin embargo, según estos mismos autores existe una excepción: "los menores de 18 años extranjeros, independientemente de que los padres estén en situación administrativa irregular o no, recibirán asistencia sanitaria en las mismas condiciones que los españoles".

Ante esta situación podemos decir que uno de los colectivos más vulnerables son las mujeres víctimas de violencia de género en situación de irregularidad o mujeres Serv. Soc. \& Saúde, Campinas, SP v. 14, n. 2 (20), p. 179-200, jul./dez. 2015 ISSN 1676-6806 
víctimas de trata. Distintos autores han comentado la situación de especial vulnerabilidad en la que quedan estas mujeres, tras la entrada en vigor del Real Decretoley 16/2012. Esta privación del derecho a la salud hace que no puedan ser atendidas por los centros de atención primaria y hospitalaria, los cuales son ideales para la detección y seguimiento de los casos de trata (MÉDICOS DEL MUNDO 2014; AMNISTÍA INTERNACIONAL, 2012).

Siguiendo las aportaciones de Amnistía Internacional (2014), Lema (2014), Médicos del Mundo (2014), Médicos del Mundo (2013) la atención sanitaria a estas mujeres víctimas de trata queda restringida únicamente a aquellas que se encuentren en el denominado “periodo de restablecimiento y reflexión”, el cual se concede en el caso de que necesiten tomarse un tiempo para decidir si quieren o no colaborar con las autoridades en la persecución del delito.

Sin embargo, desde la práctica se considera que este criterio es demasiado restrictivo y casi inaplicable pues son escasas las que se acogen a esta opción (LEMA, 2014). Podemos verlo reflejado en datos que nos ofrece la propia Fiscalía General del Estado en su memoria del 2011 (citado por AMNISTÍA INTERNACIONAL, 2012, p. 1):

[....] se detectaron 15.075 personas en situación de riesgo de trata, de las cuales solo fueron identificadas como víctimas de explotación sexual y trata 1.641. Y únicamente a 43 de ellas se les ofreció el periodo de reflexión.

Se puede afirmar que existe un descenso en el número de víctimas de trata identificadas ya que se les niega el acceso al sistema sanitario siendo ésta una de las vías para la detección de las mismas según nos indica el Protocolo Marco de Protección de las Víctimas de Trata de Seres Humanos aprobado por el Gobierno el 28 de octubre de 2011. Esta afirmación es corroborada con los datos del Proyecto Esperanza (2013, p. 1) donde explican el descenso, tanto de mujeres víctimas de trata identificadas como del número de periodos de reflexión:

[...] comparando los datos en los años 2011 y 2012 el número de mujeres víctimas de trata identificadas ha descendido un $10 \%$, pasando de 1082 en el año 2011 a 976 en 2012. También ha descendido el número de los periodos de restablecimiento y reflexión ofrecidos a estas mujeres, de 763 a 377, y el número de los concedidos, que se redujo de los 98 a 81 ( p. 1). 
Esta reforma da lugar a consecuencias perjudiciales que suponen un verdadero peligro para la salud de la propia mujer, como es el caso de enfermedades crónicas y mentales, o poniendo en peligro la salud pública, como es el caso de enfermedades de transmisión sexual (VIH/SIDA), hepatitis, tuberculosis... debido a la falta de atención y tratamiento de las mimas (LEMA, 2014; MÉDICOS DEL MUNDO, 2014; AMNISTÍA INTERNACIONAL, 2012).

Además, no se pueden ignorar las repercusiones sobre la salud sexual y reproductiva que tendrá la falta de asistencia sanitaria a estas mujeres: "desde la ausencia de pruebas diagnósticas y de screening para la detección precoz de enfermedades ginecológicas hasta la falta de cobertura sanitaria en casos de interrupción voluntaria del embarazo" (LEMA, 2014, p. 110).

Tomando como referencia a varios autores podemos decir, que al mismo tiempo que impera el Real Decreto-ley 16/2012 en España, cada Comunidad Autónoma de la misma tiene un margen, en sus competencias, para seguir las directrices de esta Ley, establecer otros requisitos o atender a las personas inmigrantes en situación irregular, aunque no tengan la tarjeta sanitaria (LEMA, 2014; MÉDICOS DEL MUNDO, 2014).

Según Médicos del Mundo (2014) y Amnistía Internacional (2013) se puede apreciar que el acceso el sistema sanitario es diferente según las distintitas Comunidades Autónomas:

a. 10 CC.AA proponen medidas para proporcionar tarjeta autonómica sanitaria a las personas inmigrantes en situación administrativa irregular:

- 8 de ellas en forma de "programa especial” específico para el colectivo de personas no aseguradas ni beneficiaras sin recursos: Aragón, Canarias, Cantabria, Cataluña, Extremadura, Galicia y Valencia.

- 2 de ellas reconociendo el derecho a la atención sanitaria en condiciones iguales al resto de la población: Andalucía y Asturias.

b. 9 han declarado que aplicarán el Real Decreto-ley 16/2012. El resto de Comunidades Autónomas cobrarán por los servicios sanitarios a los inmigrantes que no tengan la condición de “asegurados”. 
Vemos como las actuaciones emprendidas por las Comunidades Autónomas son heterogéneas, afrontando de manera desigual el impacto de la reforma sanitaria y ocasionando por ello importantes disparidades en salud dentro de España. Concretamente, apreciamos como Andalucía sigue atendiendo a los inmigrantes en situación irregular sin dejar que el Real Decreto le afecte.

Desplazándonos al colectivo de mujeres migrantes víctimas de trata podemos decir que con la excepción de Andalucía y Asturias, se ha reducido la capacidad de combatir la violencia de género desde el ámbito sanitario.

Médicos del Mundo (2014) advierte que "limitar a los servicios de urgencias la posibilidad de detección significa un retroceso en la estrategia para reducir esta forma de violación contra los derechos humanos de las mujeres" (p. 18).

En el caso de Andalucía, las mujeres posibles víctimas de trata encuentran una vía de acceso a la atención sanitaria (primaria y especializada) y a la Tarjeta Sanitaria. Esto se explicita en la Ley Andaluza de Salud en su artículo 3 (citado por Médicos del Mundo, 2014) reconociendo el derecho a las prestaciones y servicios de salud a las personas españolas y extranjeras en situación administrativa irregular.

En definitiva, entendemos que la reforma sanitaria no se justifica: ni desde el punto de vista de Derechos Humanos, ni económico, ni de salud pública ni desde la ética. Tras el análisis de esta perspectiva normativa, podemos concluir que actualmente el derecho a la salud no está siendo considerado como un derecho universal en muchas de las Comunidades Autónomas de España, afectando entre otros, a mujeres inmigrantes posibles víctimas de trata.

\section{INTERVENCIÓN DESDE EL TRABAJO SOCIAL}

La salud de las mujeres migrantes debe ser abordada desde la interdisciplinariedad ya que no es cosa de una sola ciencia, sino que se necesita que varias disciplinas (tanto naturales como sociales) interactúen y se integren entre sí para comprenderla y alcanzarla (FERNÁNDEZ-LÓPEZ y otros, 2010; ALCÁNTARA, 2008). Por lo tanto la salud no solo atañe a los médicos sino que es necesaria la actuación de varios profesionales entre los cuales destaca el Trabajador Social Sanitario. De manera general y aproximada, podemos decir que los Trabajadores Sociales que trabajan en los distintos nivel de salud tienen un papel clave para la detección y atención Serv. Soc. \& Saúde, Campinas, SP v.15, n. 2 (22), p. 179-200, jul./dez. 2016 ISSN 1676-6806 
de mujeres posibles víctimas de trata. Desde este sentido y después de todo lo expuesto sobre las graves vulneraciones de derechos que sufren estas mujeres el Trabajo Social tendrá que actuar en la prevención, atención e inserción social. Siguiendo a Cordero, Cruz y Sánchez (2012, p.79-81), podemos destacar las siguientes actuaciones:

A nivel preventivo los trabajadores sociales pueden proponer medidas, en materia de políticas sociales, que traten de atajar las causas estructurales que generan vulnerabilidad en personas susceptibles de padecer trata. En este sentido, desde el Trabajo Social se alerta de la importancia de trabajar sobre factores como la pobreza y su feminización, la globalización neoliberal, la falta de acceso a la educación, el desempleo, las creencias y valores patriarcales y las leyes migratorias entre otras. Se trata pues de desvelar la complejidad del fenómeno que se presenta como un reto para los/as profesionales del Trabajo Social, en pro de la defensa de los derechos humanos y más concretamente del derecho a la salud de las personas vulnerables como son las mujeres migrantes. A este nivel, también es fundamental la formación, capacitación y sensibilización por parte de los trabajadores sociales a todos los profesionales que pueden verse implicados en la identificación de posibles víctimas de trata en el contexto sanitario. El trabajo de sociosanitario en el ámbito de las migraciones y de la Cooperación Internacional permitirá actuar en los países de origen sensibilizando a las poblaciones vulnerables y los profesionales que trabajan con ellas.

En el nivel de atención, los trabajadores sociales se encuentran en una posición privilegiada para identificar a las víctimas, pues se enfrentan cada día con situaciones de vulnerabilidad en los servicios sociosanitarios. La identificación es posible por dos vías: una directa, porque la persona lo manifieste abiertamente o a través de una persona de su confianza; otra indirecta, a través de la presencia de indicadores físicos, psicológicos y contextuales, para aquellos casos de demandas inespecífica que a veces tienen que ver con ayudas puntuales. Desde el Trabajo Social sabemos que esto tan solo puede ser la punta del iceberg en cuyo fondo pueden existir otras situaciones de violencia.

A groso modo, las diversas funciones de los profesionales podrían ser las siguientes, teniendo en cuenta que éstas variarán dependiendo de las instituciones desde la que trabajen:

- Valoración socio-familiar de la mujer posible víctima de trata.

Serv. Soc. \& Saúde, Campinas, SP v. 14, n. 2 (20), p. 179-200, jul./dez. 2015 ISSN 1676-6806 
- Apoyo psicosocial.

- Trabajo de promoción de la salud en calle en pisos, clubs, zonas de carretera...

- Información y asesoramiento: programas de salud, tarjeta sanitaria, información sobre los derechos que tienen de acceso a la salud, información sobre salud sexual y reproductiva, centros sociales, folletos informativos sobre $\mathrm{VIH}, \ldots$

- Facilitar material preventivo: preservativos, lubricantes,...

- Gestión de recursos: tarjeta sanitaria, prueba de detección del VIH,...

- Gestión de talleres de promoción integral: iniciación en TIC's, educación para la salud, talleres de habilidades sociales, de autoestima, de empoderamiento, orientación laboral de forma personalizada y grupal, educación básica: matemáticas, lengua, etc.

- Orientación laboral y técnicas de búsqueda de empleo.

- Realizar Historias Sociales, Informes Sociales...

- Coordinación/ Derivación con dispositivos especializados en este colectivo y otros dispositivos sociosanitarios.

- Seguimiento Social.

Teniendo presente los principios éticos de la profesión del Trabajo Social (FITS) proponemos facilitar una atención más humanista a las víctimas de trata. De hecho, si los procedimientos no se cuidan a través de actitudes de afabilidad y empatía por parte de los/as profesionales que intervienen, se pueden originar dificultades para obtener evidencias que salvaguarden a las víctimas y generar el procesamiento de la persona sospechosa de haber cometido un delito de trata. Para el Trabajo Social

[...] una tarea impostergable en la lucha por los derechos humanos, tiene que ver con la acciones transformadoras que provoquen procesos culturales no re-victimizantes, que tiendan a superar los prejuicios y los estereotipos sociales (como la sutil culpabilización de las víctimas por la situación vivida), a la vez que sensibilice a las personas implicadas en la lucha contra la trata (policías, jueces, funcionarios, etc.) para que la víctima pueda ingresar en procesos de construcción de reconocimiento, personal y social con entornos seguros y sanadores, para ella y sus familias (CORDERO, 2014, p. 9). 


\section{CONCLUSIONES}

Podemos concluir en que existen ciertos obstáculos subyacentes de las leyes y normativas que dificultan el acceso y atención en los servicios sanitarios a las mujeres inmigrantes posibles víctimas de trata en España. Aun existiendo en España el Real Decreto-ley 16/2012, de 20 de abril, donde la atención se sostiene por la condición de “asegurados”, podemos decir que en Andalucía el acceso a los mismos es universal y gratuito. Sin embargo, los profesionales sociosanitarios en Andalucía o en otras CC.AA podrían tener desconocimiento acerca de los cambios normativos y administrativos que se han producido con la entrada del mismo, estando desinformados bien porque no saben las actuaciones y criterios que su Comunidad Autónoma aplica en relación a este Decreto o, por otro lado, porque piensan que esta Ley se aplica por igual en todas las Comunidades Autónomas, dando lugar a situaciones de exclusión grave e injustificadas. Por ello, la formación y sensibilización juegan un papel bastante importante.

También es necesario que los profesionales del Trabajo Social sensibilicen a otros profesionales para trabajar de forma colaborativa en la prevención y atención de los derechos que tiene las mujeres migrantes. En el caso de Andalucía sería necesario que informaran a éstas sobre la universalidad y gratuidad de la atención sanitaria ya que las mujeres inmigrantes irregulares, en su mayoría, desconocen la especificidad de Andalucía en la aplicación del Real Decreto y por tanto, no acceden a los recursos públicos de salud.

Para finalizar, consideramos que las intervenciones e investigaciones en torno a este tema deben abordarse de manera multidisciplinar ya que en esta materia se vulneran muchos Derechos Humanos de las mujeres víctimas de trata y son muchas las variables a la hora de abordar una solución. Además, recalcar que los profesionales, debieran trabajar siempre desde un enfoque crítico de los derechos humanos, la dignidad de las personas y la justicia social, resultando clave para el éxito de la atención de estas mujeres objeto de trata que éstos se involucren en la búsqueda de una respuesta satisfactoria.

Recebido em 09.12.2016 - Aprovado em 19.12.2016 


\section{REFERENCIAS}

ABDULRAHEEM, S. y OLADIPO, R. Trafficking in women and children: A hidden health and social problem in Nigeria. International Journal of Sociology and Anthropology, 2(3), 2010, pp. 34-39.

ACIÉN GONZÁLEZ, E. y CHECA y Olmos, F. La actualidad del abordaje de la trata de personas para la prostitución forzada en España: El Plan Integral y sus implicaciones para trabajadoras del sexo inmigradas. Gazeta de Antropología, (27) 9, 2011, pp. 1-19. ALCÁNTARA MORENO, G.; La definición de salud de la Organización Mundial de la Salud y la interdisciplinariedad. Sapiens Revista Universitaria de Investigación, 9(1), 2008, pp. 93-107.

AMNISTÍA INTERNACIONAL. Se mantiene la exclusión sanitaria de las personas inmigrantes en situación irregular, sin atender las recomendaciones internacionales, 2014. Consultado en https://www.es.amnesty.org/noticias/noticias/articulo/se-mantienela-exclusion-sanitaria-de-las-personas-inmigrantes-en-situacion-irregular-sin-atender/. Fecha de consulta: 25/12/2015.

AMNISTÍA INTERNACIONAL. Con la reforma sanitaria entra en vigor una nueva violación de derechos humanos, $2012 . \quad$ Consultado en https://www.es.amnesty.org/noticias/noticias/articulo/con-la-reforma-sanitaria-entra-envigor-una-nueva-violacion-de-derechos-humanos/. Fecha de consulta: 15/12/2015.

ANGUITA OLMEDO, C. El tráfico ilegal de seres humanos para la explotación sexual y laboral: la esclavitud del siglo XXI. Nómadas. Revista Crítica de Ciencias Sociales y Jurídicas, 15(1), 2007, pp. 3-17.

ASOCIACIÓN COMISIÓN CATÓLICA ESPAÑOLA DE MIGRACIÓN (ACCEM). Guía de autocuidado y autodefensa para mujeres víctimas de trata con fines de explotación sexual, 2011. Consultado en

http://www.accem.es/ficheros/documentos/pdf_trata/guia_AutocuidadoAutodefensaExp Sexual.pdf. Fecha de consulta: 27/06/2015.

CASTEL, R. La discriminación negativa: ¿ciudadanos o indígenas? Barcelona: Editorial Hacer, 2010.

CASTELLANOS TORRES, E. y RANEA TRIVIÑO, B. La perspectiva de género y de los Derechos Humanos en el análisis de la prostitución y la trata de mujeres con fines de 
explotación sexual. Una aproximación desde la voz de las propias mujeres. Dilemata, (16), 2014, pp. 161-179.

CONSEJO EUROPEO. Convenio del Consejo de Europa sobre la lucha contra la trata de seres humanos. 2005. Consultado en

http://www.accem.es/ficheros/documentos/pdf_trata/Convenio_Consejo_de_Europa.pdf Fecha de consulta: 27/06/2015.

CONSEJO GENERAL DEL PODER JUDICIAL. Protocolo Marco de Protección de las Víctimas de Trata de Seres Humanos, 2011.

CORDERO RAMOS, N. Trata con fines de explotación sexual. Derechos humanos que mal-tratan a las humanas. Gazeta de Antropología, 30(3), 2014.

CORDERO, N.; CRUZ P. y Sánchez I. Trata de personas, dignidad y Derechos Humanos en Costa Rica: Aportes desde el trabajo social. IX Congreso Nacional de Facultades de Trabajo Social, Jaén. Febrero, 2012.

CASTRO RODRÍGUEZ, M. C. La trata de personas: la esclavitud más antigua del mundo", Documentos de trabajo social. Revista de Trabajo y Acción Social. 23 (51), 2012, pp. 447-457.

DEFENSOR DEL MENOR. Informe al Parlamento, 2013. Consultado en http://www.observatoriodelainfancia.es/oia/esp/descargar.aspx?id=4334\&tipo=documen to. Fecha de consulta: 27/11/2016.

DEFENSOR DEL PUEBLO. La trata de seres humanos en España: víctimas invisibles, 2012. Consultado en http://www.defensordelpueblo.es/es/Documentacion/Publicaciones/monografico/Docum entacion/Informe_Defensor_del_Pueblo_trata.pdf. Fecha de consulta: 21/06/2015. ESPAÑA. MINISTERIO DE SANIDAD. Servicios Sociales e Igualdad 2015-2018; plan integral de lucha contra la trata de mujeres y niñas con fines de explotación sexual, 2015-2018. Consultado en http://www.violenciagenero.msssi.gob.es/planActuacion/planContraExplotacionSexual/ docs/Plan_Integral_Trata_18_Septiembre2015_2018.pdf. Fecha de consulta: 25/11/2016.

ESPAÑA. Ley 33/2011, de 4 de octubre, General de Salud Pública, BOE, 240, 2011. ESPAÑA. LEY 16/2003, de 28 de mayo, de cohesión y calidad del Sistema Nacional de Salud, BOE, 128, 2003.

Serv. Soc. \& Saúde, Campinas, SP v. 14, n. 2 (20), p. 179-200, jul./dez. 2015 ISSN 1676-6806 
ESPAÑA. Ley Orgánica 4/2000, de 11 de enero, sobre derechos y libertades de los extranjeros en España y su integración social", BOE, 10, 2000.

ESPAÑA. Ley 14/1986 de 25 de abril, General de Sanidad, BOE, 102, 1986.

ESPAÑA. REAL DECRETO-LEY 16/2012, de 20 de abril, de medidas urgentes para garantizar la sostenibilidad del Sistema Nacional de Salud y mejorar la calidad y seguridad de sus prestaciones, BOE, 98, 2012.

FERNÁNDEZ-LÓPEZ, J. A., FERNÁNDEZ-FIDALGO, M., y CIEZA, A. Los conceptos de calidad de vida, salud y bienestar analizados desde la perspectiva de la clasificación internacional del funcionamiento (CIF). Revista Española de Salud Pública, 84(2), 2010, pp. 169-184.

GARCÍA CUESTA, S. La trata en España: Una interpretación de los Derechos Humanos en perspectiva de género. Dilemata, (10), 2012, pp. 45-64.

GROSFOGUEL, R. Descolonización de la vida política y los estudios poscoloniales: transmodernidad, pensamiento de colonial y colonialidad global. En B. Sousa y M. P. Meneses, M.P (edit.) Epistemologías del Sur (Perspectivas), 2014, pp. 373-406. Akal: Madrid

HERRERA, J. Los derechos humanos como productos culturales. Madrid: Catarata, 2005.

JULIANO, D. El trabajo sexual en la mira. Polémicas y estereotipos. Cadernos Pagu, 2005, n ${ }^{\circ}$ 25: 79-106.

LEMA TOMÉ, M. La reforma sanitaria en España: Especial referencia a la población inmigrante en situación administrativa irregular, EUNOMÍA. Revista en Cultura de la Legalidad, 2014, pp. 95-115.

MALENO, H. Telón de fondo de las políticas migratorias. Rompamos el silencio. 2010. Consultado en http://www.rompamoselsilencio.net/2010/?Telon-de-fondo-de-laspoliticas. Fecha de consulta: 20/11/2016

LUGONES, M. Colonialidad y Género. Tabula Rasa, 2008, n 9, julio-diciembre, Bogotá-Colombia, pp. 73-101.

MÉDICOS DEL MUNDO. Dos años de reforma sanitaria: más vidas humanas en riesgo, 2014. Consultado en

https://www.medicosdelmundo.org/index.php/mod.documentos/mem.descargar/fichero. documentos_Impacto-Reforma-Sanitaria-Medicos-del-

Mundo_3ec0bdf9\%232E\%23pdf. Fecha de consulta: 20/04/2015. 
MÉDICOS DEL MUNDO. El impacto de la reforma sanitaria sobre el Derecho a la

Salud, 2013. Consultado en http://www.medicosdelmundo.es/derechoacurar/wpcontent/uploads/2012/11/Resumen-del-impacto-de-la-reforma-sanitaria-en-el-derechoa-la-salud-de-la-poblaci\%C3\%B3n-inmigrante-Casos-documentados.-sin-anexos-sincasos.pdf. Fecha de consulta: 20/04/2015.

NACIONES UNIDAS (ONU); Protocolo para prevenir, reprimir y sancionar la trata de personas, especialmente mujeres y niños, que complementa la convención de las naciones unidas contra la delincuencia organizada transnacional, 2000. Consultado en http://www.uncjin.org/Documents/Conventions/dcatoc/final_documents_2/convention \%20traff_spa.pdf. Fecha de consulta: 27/02/2015.

ORGANIZACIÓN MUNDIAL DE LA SALUD. Constitución de la Organización Mundial de la Salud, 1948. Consultado en http://www.who.int/governance/eb/who_constitution_sp.pdf. Fecha de consulta: Extraído el 03/04/2015.

PROYECTO ESPERANZA. La protección a las víctimas de Trata en España aún es insuficiente, 2013. Consultado en http://www.proyectoesperanza.org/la-proteccion-alas-victimas-de-trata-en-espana-aun-es-insuficiente/. Fecha de consulta: 25/01/2016. QUIJANO, A. (2014). Colonialidad del poder y clasificación social. En B. Sousa y M. P. Meneses, M.P. (edit.) Epistemologías del Sur (Perspectivas (67-108) Akal: Madrid

SÁNCHEZ, D. Y SENENT, J.A. Teoría crítica del derecho. Nuevos horizontes. San Luis-Aguascalientes: Universidad Autónoma San Luis. 2013.

SOLANA, J. L.; Movimientos migratorios, trabajadoras inmigrantes y empleo en la prostitución. Documentación social, 144, 2007, pp. 37-57.

SOUSA, B Y MENESES, M.P. Epistemologías del Sur. (Perspectivas). Akal: Madrid. 2014.

UNODC. Informe mundial sobre la trata de personas. 2014. Consultado en https://www.unodc.org/documents/data-andanalysis/glotip/GLOTIP14_ExSum_spanish.pdf. Fecha de consulta: 27/11/2016. 